\title{
Baltasar Gracián: verdad y retruécano
}

\author{
Ana María Martínez de la Escalera
}

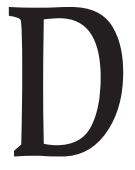

\section{e Baltasar Gracián, autor}

Este jesuita, cuya complexión colérica un único retrato suyo -hoy puesto en duda- nos deja diagnosticar, "agrio y melancólico", aun para sus compañeros de orden, nació en 1601 en Belmonte, pueblo de la comunidad de Calatayud, en Aragón, y murió en 1658, sin haber abandonado España, la academia y sus votos. Se cuenta, sin embargo, que en una ocasión, ya maduro, vaciló. La Compañía de Jesús se aseguró de no perderlo, hemos de creer que por su valía, a pesar de haberse mostrado en otras ocasiones un tanto rebelde a la autoridad. Es sabido que en ese entonces un sacerdote no podía publicar sin el consentimiento de sus superiores: Gracián, haciendo caso omiso del principio de obediencia se atrevió a editar "por sus fueros" los primeros libros. Fue castigado, lo cual no le impediría reincidir.

En el colegio de Tarazona, donde iría a parar en un momento de una vida poco aventurera (si descontamos la vez que fue requerido para asistir a los soldados sitiados en Lérida por el ejército francés), se opinaba de él que era “...de buen ingenio, de juicio módico, de prudencia también módica, de experiencia suficiente, bueno en letras y con talento para todo ministerio”. Eso del juicio módico y la prudencia también módica no parece ser sino la verdad estricta: en una corte en que el elogio era común y necesario, y la forma más expedita de erigir y derrumbar obras y autores, Gracián extiende sólo dos aprobaciones a sendos libros de sus contemporáneos, una al Entretenimiento de las musas, de Francisco de la Torre, y la otra a la reimpresión de los Proverbios morales de Alonso de Barros, publicados originalmente en 1598. Hay que leer, tras la afectación un poco alambicada que el elogio ostentaba en esos días, una ponderación muy bien medida, un manejo parco del encomio, aun en el caso del Entretenimiento que parece haberle satisfecho, como lector avezado, enormemente. Como lo expresaron sus colegas de la 
Compañía de Jesús, la prudencia ${ }^{1}$ y el juicio (crisi) gracianos serían siempre económicos.

La parquedad no está reñida con el artilugio retórico, a pesar de lo que suele pensarse. La inclinación del aragonés hacia la retórica se manifestó siendo maestro en colegios de la orden y antes de dedicarse por entero, según se dice, a la teología o filosofía moral. Conviene dejar en suspenso esta última afirmación ya que, como habrá de argumentarse un poco más adelante, la complejidad problemática y crítica de la retórica graciana parece incluso mayor que la de sus escritos éticos, lo cual no ha impedido que pasara desapercibida (o al menos minusvalorada) para la mayoría de los estudiosos y lectores dedicados. ${ }^{2}$ La inclinación por la retórica o artes del discurso fue tan crítica como obsesiva a lo largo de todas sus empresas, ${ }^{3}$ y, sin embargo, no puede achacársele al siglo o a la época sino a una unión circunstancial de factores. Lecturas de Cicerón y Horacio se anudaron en los cursos de retórica a un fuerte empeño crítico, revisionista; un conocimiento profundo de la posición

${ }^{1}$ La prudencia barroca, como significados predicados de textos y comportamientos, fue ciertamente el producto de la influencia del pensamiento aristotélico sobre la concepción del arte, que según afirma Argan sería el factor esencial de la superación del canon formal y por tanto del neoplatonismo miguelangelesco. Este planteamiento, sin embargo, tiene que ver menos con una historia de las vicisitudes del aristotelismo que con una genealogía de la retórica, como disciplina(s) y como artes del discurso. Sin menospreciar el problema que representa hablar del pensamiento aristotélico como si se tratara de una unidad homogénea de obra e ideas, es evidente que aun cuando los autores se consideraran aristotélicos, lo que queda por examinar es la transformación semántica y de valor sufrida por el vocabulario aristotélico una vez que fue adoptado por el pensamiento barroco.

${ }^{2}$ Es frecuente leer entre aquellos autores dedicados al tema que la retórica barroca que despliega el valor de la persuasión y la técnica y el arte de persuadir sea por lo tanto una simple transposición de la Retórica aristotélica. Se explica este reduccionismo por el hecho de que la mayoría de aquellos preocupados por el periodo han sido historiadores de las ideas. Las dificultades y peligros del reduccionismo han sido criticados ampliamente por los trabajos teóricos de Foucault, e incluso por los más serios entre los historiadores; aun así, será siempre conveniente leer teóricamente a los autores barrocos, además de hacerlo tomando en cuenta su valor histórico. En Italia la vulgarización de la Retórica aristotélica fue debida a Almarò Barbaro (aunque había sido traducida al italiano en 1570 por Aníbal Caro), que unida al rescate del humanismo, ayudó a oponerse al rigor lógico de otras escuelas de pensamiento, y se sustituyó el sistema por el método. El contraste entre ambas es notorio: el pensamiento barroco reconoce el valor del decir (pronuntiatio), del comunicar, de la fuerza persuasiva del discurso (elocutio), sobre la preocupación por el objeto externo. Incluso es dable ver este énfasis en las artes figurativas; Gentile, y, por ejemplo, Giorgone y Tiziano, quienes sustituyen el binomio pintura/poesía por el de pintura/elocuencia.

${ }^{3}$ Baltasar Gracián, Agudeza y arte de ingenio. Ed., introd. y notas de Evaristo Correa Calderón. Madrid, Castalia, 1979, p. 5. 
probabilista, defendida por la Compañía, le permitió acercarse a la efectividad de lo pragmático antes que a la necesidad de la ley y la autoridad, como también al escepticismo antiguo siempre desde una cierta ironía como inclinación particular.

Se ha considerado que en oposición al ideal de armonía y proporcionalidad -canon formal y neoplatonismo miguelangelesco- que caracterizó al Renacimiento, la época barroca estuvo dominada por las autonomías en el orden de la vida científica, en las creencias religiosas, en la consecución de ideales individuales, en la filosofía (los diversos pragmatismos), sumadas a una democratización de la moral, a pesar de la Inquisición y la emergencia de las nuevas policías del continente; pero esta explicación fracasa cuando sólo consigue sustituir una categoría histórica-estética - la armonía- por otra - la pluralidad de experiencias de lo humano-; o, en cualquier caso, resulta insuficiente. ${ }^{4}$ Argan, por su parte, ha preferido dibujar un sólo aspecto del periodo barroco fijándose en la influencia del pensamiento aristotélico sobre la crítica al neoplatonismo. El interés de Argan ha sido la historia del arte, sin embargo, su interés en el aristotelismo barroco lo sitúa del lado de una escuela de interpretación a la que ha convenido resaltar el aspecto pragmático de la época sobre otras características. Estos pensadores, incluyendo a Argan, no ven tanto originalidad cuanto una manera distinta de leer los textos aristotélicos. Por otra parte, la crítica literaria y la historiografía recurren aún hoy a la oposición entre canon y pluralidad de visiones para explicar la eclosión del mundo barroco del seno del Renacimiento tardío.

La pluralidad parece una buena categoría explicativa en razón de su presentación directa al sentido o simpleza. Tal parece, además, que apela en nosotros a ciertos hábitos mentales que poco a poco se han ido instalando en nuestras maneras de pensar y preferir lo que creemos ser. La referencia a la pluralidad de experiencias, a la democratización y a las autonomías nos hacen materia especialmente receptora a la idea de barroco; solemos considerarnos a nosotros mismos como seres abiertos a los cambios, a las nuevas experiencias en el orden de lo cultural, lo científico, lo técnico, lo religioso y lo político. Hoy como antaño reviven el estoicismo, el senequismo, el escepticismo

${ }^{4}$ Justamente el problema es provocado por la expresión periodo que según un buen diccionario como el de Oxford remite a la unidad de una época, a su homogeneidad. A la inversa, se trata de contraponer a esta imagen un tanto simplista de la historia, no otra mejor o más compleja, igualmente susceptible de crítica, sino más bien mostrar lo que cualquier imagen de una época no deja observar: que hubo en suma muchos barrocos y que en la época (Siglo de Oro) no todo puede explicarse recurriendo al espíritu barroco. En la historia del arte la escuela de Warburg (i.e. Erwin Panofsky) ha sido especialmente afecta a establecer estas unidades de tiempo y espacio que sólo su escasa dimensión salvan del fracaso explicativo. 
como vías para mitigar, o al menos consolarnos, de lo que la cultura mediática llama "el malestar de fin de siglo". Esta imagen de nosotros, como aquella antigua, es, al igual que toda imagen, una ficción; imagen con todo útil y necesaria, pero, de forma similar a la ficción, una cosa no natural, no consustancial sino contingente y modificable. La Contrarreforma y el barroco no son identidades explicativas ni fácticas estables ni omniabarcantes, como tampoco lo es, para el caso, la modernidad.

Es por ello que ubicar el pensamiento graciano en las producciones típicas de la Contrarreforma o el "jesuitismo" será siempre insuficiente. Al interior de la Compañía de Jesús, en la que él profesó, solían discutirse problemas concernientes al libre albedrío y la predestinación a causa seguramente de los embates de la Reforma, bastante más determinista que ellos. El probabilismo fue, entre otras modalidades de la filosofía y la teología del momento, un importante ingrediente en la forma de argumentar graciana: no sería sin embargo la única ni la más determinante.

El movimiento probabilista sostenía que puede seguirse una opinión menos probable en contra de otra que sea evidentemente más probable. Se dice que Gracián, al no someterse a la costumbre de consultar a su orden antes de publicar un libro, aprobaba las tesis del probabilismo, aún a riesgo de su propia seguridad en las fuerzas de la Compañía, tesis que defendían que el hombre puede adoptar, desde la libertad de su conciencia, la acción menos probable. 5

${ }^{5}$ Julio Caro Baroja opina, con todas las reservas del caso, que los conversos introdujeron en la vida cotidiana del Siglo de Oro, y en especial en la vida cotidiana de lo que podría llamarse "burguesía", una serie de normas y de criterios de orden, de suerte que hasta la piedad quedaba atemperada a ciertos principios matemáticos y racionalizados que establece la práctica y ejercicio continuo de la actividad comercial. El historiador español estima que la influencia judaica debe estudiarse en relación con este asunto de la tabla de acciones buenas y malas, y también sobre la llamada moral probabilista, creación casi de teólogos españoles, que tuvo sus máximas expresiones desde fines del siglo XVI hasta mediados del XVII, y, según la cual, al calificar la bondad o maldad de las acciones humanas, se puede seguir una opinión tan sólo probable frente a la más probable. (Julio Caro Baroja, Inquisición, brujería y criptojudaísmo. Barcelona, Galaxia Gutenberg/Círculo de Lectores, 1996, pp. 35-36.) Habría así una relación entre el casuismo talmúdico y el casuismo católico. La moral que se deduce de los libros de casuística (probabilistas o laxistas), es una moral de hombres que viven en un medio social muy complejo, en que las cuestiones de honor, las violencias y las fuerzas, y los negocios insólitos, se presentan a cada individuo de una manera imperiosa y constante. (Ibid., p. 36.) Conciliar la complejidad social con la simplicidad de los preceptos universales llevaría a una solución de compromiso entre ambos. Los probabilistas, a los que Baltasar Gracián ha solido relacionarse, arribaron a una solución discutible pero interesante en su proceder: tras una suma de pacientísimos análisis de situaciones planteadas en el confesionario, siempre singulares y de consultas (véase 
Respecto a la querella entre conceptistas y culteranos, que prendió fuertemente en la vida española del Siglo de Oro, basta con decir que en la actualidad no parece tan determinante: hoy se discuten más las similitudes que las diferencias. Ángel del Río escribe que "la diferencia consiste en que el conceptismo opera sobre el pensamiento abstracto y el culteranismo sobre la sensación. Uno es racional, el otro puramente estético", 6 no obstante, esta distinción también es discutible. Pero, no desmerece el tiempo que tardaremos en comentarla.

Se considera que el conceptismo es una forma de intelectualizar una experiencia. Lo que interesa al conceptista es la relación de palabras, relación que va desde la asociación sutil a juegos de palabras sorprendentes y juegos de conceptos. Quiere relacionar ideas que están distanciadas por el uso y abuso del lenguaje hablado, y probar los límites de la palabra en un contexto escrito. Tampoco la escritura salva al escritor de los estragos del uso y abuso de las palabras: ¡qué mejor ejemplo que las mismas producciones del barroco! En Gracián, como en los conceptistas que le precedieron, la ambigüedad con la que se confronta al lector no está en la expresión sino en la interpretación. Con ello se observa un replanteamiento de la relación entre pensamiento, la lengua y los principios que rigen el uso de los mismos.

\section{Del caudal de la lengua}

La educación que los jóvenes recibían en la época les enseñaba que el propósito de la lectura era conseguido una vez que se dominaba la distinción entre la forma y el contenido. Como todo humanista, Gracián apreciaba el papel de la enseñanza como forma de transmisión y conservación de la sabiduría, pero resentía el papel desempeñado por la lectura en la misma. Para él la lectura era el modelo de la comprensión: la producción de un texto o significado a partir de elementos de uso común: refranes, poemas de otras plumas, dichos populares. La memoria colectiva, oral y registrada por la escritura, son

Gonzalo de Palma, Obras completas. Madrid, Biblioteca de Autores Españoles, CXLIV, p. 14, citado en J. Caro Baroja, op. cit., p. 36), se llegan a soluciones donde la modalidad de expresión (por ejemplo, la distinctio o el pilpul hebreo) es determinante. Se trata, pues, de soluciones pragmáticas, es decir, de compromiso donde el análisis del uso es la piedra de toque. Es decir, no se reduce esta casuística a la actitud parelela del rabino o del confesor ante un problema de conciencia expuesto por un fiel, sino que vemos aquí la influencia de situaciones más técnicas si cabe: me refiero, por supuesto a ciertas reglas retóricas.

${ }^{6}$ Vid. Ángel del Río, Moralistas castellanos. Selec. y estudio prel. de Á. del R. Barcelona, Barna, 1954. 
reutilizadas por el pensamiento como si se trataran de signos, como demuestra en Agudeza y arte de ingenio. Parcial a la expresión "caudal de la lengua" para referirse a esa materia previamente interpretada por su cultura española y clásica, al mismo tiempo Baltasar Gracián ponía especial énfasis en el carácter inventivo de las lecturas. La filología y la gramática castellanas eran forzadas con el fin de lograr resultados novedosos y críticos: diáforas y símiles, ironías, sinécdoques, retruécanos, entimemas y paradojas nutrían sus alegorías. Un ejemplo pertinente es, como se sabe, el "gusto". Lengua y gusto, expresión e ingenio intercambian sus predicados tras haberlos identificado como funciones de la oralidad, de la lengua orgánica y el paladar. Oralidad y sabiduría son puestas así en evidencia, mostradas sus diferencias y similitudes, su reversibilidad, al instaurar su cercanía en el discurso. Ello sólo es posible si cada elemento del discurso puede sustituir, paradigmática y sintagmáticamente, cualquier otro, gracias a que la lengua es caudal: riqueza y peligro que amenaza ahogar en sus aguas turbulentas al incauto que se ha dejado seducir. Caudal nombra así el tesoro de implicaciones intertextuales y la historia de la lengua española. Caudal es en Gracián la fortuna y la fama de su lengua.

Es manifiesto el interés demostrado por el jesuita por afinar el uso del idioma español sin desmerecer el lugar que otras lenguas ostentan en el panorama de la cultura barroca. Lo que es más, es en la traducción, en la comparación sintáctica y retórica con otras letras europeas que el uso del castellano se fortifica.

Encontramos en Gracián una defensa de la identidad de lenguaje por la fuerza del estilo, del ethos o idiosincrasia de lo español, por la exaltación de la raigambre. Raigambre que él encontraba en España, en la Compañía de Jesús, en Aragón y, finalmente, en la lengua castellana, en la que leyó y escribió.

\section{De la fama a las sutilezas de la historia intelectual}

¿Puede decirse que la obra de Baltasar Gracián tiene importancia en la historia de la retórica, o bien sólo para la historia de la retórica española? ¿Consiste su valor en rendir testimonio inequívoco de un cambio de mentalidad respecto a las relaciones entre la retórica, la epistemología, la lógica y la poesía? ¿Es Baltasar Gracián un buen recopilador del alma anónima de la tradición, como lo fue Quintiliano, aquel otro español célebre? ¿Se limita el jesuita a acoger el pensamiento de Marcial, Cicerón o, a la inversa, propone algo en lo que debiéramos fijarnos tanto si somos filósofos como filólogos? ¿Es haber referido el caudal o tesoro de sabiduría a la historia y vicisitudes del idioma español lo que nos atrae y persuade o hay algo más "universal" en sus afirmaciones, es decir, algo que modifica la idea que tenemos sobre la historia intelectual de occidente? 
Lo que la época de Felipe II llamó honra, le llamamos nosotros fama, gracias a una transformación semántica que acumula problemas, y por tanto multiplica preguntas en lugar de reducirlas. ¿Qué es, pues, la fama de un texto hoy, a diferencia de una fama de entonces cuando fue escrito? Probablemente encontremos la respuesta a esta última interrogante en la idea de una sobrevida del texto más allá de su tiempo, en la idea de una repercusión de la obra más allá de sí misma, en la idea de un sentido que sólo puede ser constituido como experiencia fenomenológica siguiendo el orden de la temporalidad.

Es indudable que en su época, Gracián fue celebrado por muchos, emulado por otros y, como suele acontecer, vituperado por otros más, pero para nuestro asombro, esas manifestaciones se presentan aún en nuestros días con igual fuerza. Jorge Luis Borges confeccionó un poema al que dio por título Baltasar Gracián; no se lo dedicó a su memoria, sino a su vituperio. Debió haberlo escrito allá por los años veintes; pero una petición urgente de Reyes y Díez-Canedo, en 1969, lo instó a publicarlo junto con otros poemas del periodo, único entre los versos. La recopilación lleva el nombre de El otro, el mismo. En forma muy semejante al breve ensayo escrito en 1930, Borges carga, inmisericorde, contra el jesuita aragonés. "Laberintos, retruécanos, emblemas, / Helada y laboriosa nadería, / Fue para este jesuita la poesía, / Reducida por él a estratagemas. / No hubo música en su alma; sólo un vano / Herbario de metáforas y argucias / Y la veneración de las astucias / Y el desdén de lo humano y sobrehumano". 7

El desprecio borgiano hacia un poeta que puede enhebrar palabras como cuentas en un collar produciendo "naderías", o "reduciendo la poesía a estratagemas" está aparejado con la presunción de que el lenguaje librado a sí mismo corre el riesgo de acabar en meras argucias muy bien ordenadas. Creía el argentino que es lo humano lo que el lenguaje debe decir en vez de hablar de sí mismo. Pero otro riesgo, que Borges se abstuvo de correr con su poesía y su prosa, ha sido la ingenuidad filantrópica (Aristóteles) y sentimental (Elliot) de la poesía y el lenguaje. Se trata esta ingenuidad de un tipo muy conocido de convicción expresiva o ingenuidad de la expresión que junto con la ingenuidad de la referencia retienen la suposición platónica que encontramos en el Cratilo de que entre las palabras y las cosas habría una relación unívoca o al menos existiría algo así como la posibilidad de la plenitud y univocidad del sentido. Esta convicción se opone a la que nutre la escritura conceptista según la cual el sentido es la producción contingente del significado, jamás una entidad ontológica.

${ }^{7}$ Jorge Luis Borges, "El otro, el mismo", en Obra poética. Madrid, Alianza/Emecé, 1972, pp. 143-144. 
Si a Borges le pudo parecer excesivo el sintagma gracianesco "Gallinas de los campos celestiales" para nombrar a las estrellas, ello puede ser prueba no del mal gusto del aragonés sino del exceso sentimental del argentino, para el cual las estrellas seguramente tienen una misión más alta que picotear la bóveda celeste. Si "gallinas" y "estrellas" son difíciles de asociar no es en razón de las diferencias de sus respectivas esencias y accidentes sino a causa de lo inverosímil que resulta a nuestra ingenuidad referencial. Los conceptistas opinaban que lo inverosímil de las asociaciones permitía al lector ir más allá de la ingenuidad de la referencia, hacia la acción del entendimiento que trabaja con el lenguaje, a su vez materia e instrumento de la significación. Es esta condición paradójica del lenguaje, ser a la vez materia e instrumento donde trabaja la significación lo que tuvo encandilados a los sofistas, a los humanistas y a los poetas del barroco español. También supieron hacer uso de esa otra valiosa paradoja que es el verbo. Paradoja lo llamaron; que pese a ser de distinta naturaleza que las cosas, tenía un poder de convencimiento mayor que ellas mismas. Así, lo que a Borges le pareció un merecido castigo es, a mi entender, una fortuna: "Dado a sus temas / Minúsculos, Gracián no vio la gloria / Y sigue resolviendo en la memoria / Laberintos, retruécanos y emblemas". ${ }^{8}$ Lo minúsculo de sus temas, como las Gallinas de los campos celestiales comparadas a la universalidad del sintagma Sol de Dios, del tema de la Verdad, de los Esplendores y arquetipos platónicos, fue precisamente lo que la crítica conceptista pretendió defender. Frente al pensamiento que reflexiona a partir de tesis universales el conceptismo pedía al poeta que se reflexionara desde la hipótesis, singular y contingente. El poeta argentino acierta cuando acusa a Gracián de ser opositor tanto de la poíesis platónica como de la interpretación del lenguaje en el Cratilo. Como tantas veces se ha dicho con menos estilo que Borges, la crítica barroca se alza contra el neoplatonismo; pero ello no la vuelve tampoco defensora del aristotelismo. Que dos interpretaciones de la retórica coincidan en su antiplatonismo no quiere decir que coincidan en lo demás. El conceptismo del jesuita está más emparentado con un arte del significado que con una teoría del sentido. La agudeza y el ingenio, el concepto y la astucia, el reparo, la crisis y la crítica son caminos del significado no la finalidad del sentido.

Otra vez Jorge Luis Borges publica, en 1930, una diatriba que se inscribía en la querella famosa que sostuvieron por esos años los grupos de Boedo y de Florida. ${ }^{9}$ El poeta argentino desautoriza con irresistible fuerza la "superstición del estilo" que caracteriza al público y a algunos contemporáneos que dicen profesar su oficio; es a no dudarlo un claro ejemplo de lo que hoy se llama

${ }^{8}$ Idem. El subrayado es nuestro.

${ }^{9}$ J. L. Borges, Discusión. Madrid, Alianza, 1976, pp. 39-43. 
"antirretórica explícita". El ensayo, que no va dirigido contra Gracián, lo menciona al menos en dos ocasiones como ejemplo de lo que no debe hacerse. El lector es conminado a no permitirse la supersticiosa ética del estilo, mal comparable -se espera que el lector ilustrado piense - al que la superstición ocasiona en la buena ciencia. Borges estaba tan interesado, como Gracián lo estuviera en su momento, en pulir el caudal de la lengua española mediante la expulsión de los sedimentos del mal uso y del abuso de las palabras, las expresiones o las fórmulas. Desconfían ambos del espejismo de los tropos y los poderes persuasivos de la metáfora. Escribió Gracián en su Agudeza que "diferencia hay entre todas las composiciones antiguas y las modernas, que aquéllas todo lo echaban en concepto, y así están llenas de alma y viveza ingeniosa; éstas, toda su eminencia ponen en las hojas de las palabras, en la oscuridad de la frase, en lo culto del estilo; y así, no tienen tanto fruto de agudeza..."10

Y propone el ejemplo ${ }^{11}$ de una redondilla, perfección de agudezas: "En mi grave sufrimiento, / no hay dolor más desigual, / que ser sólo el pensamiento, / el testigo de mi mal". (Diego de San Pedro)

Pero hoy leemos a Borges, cuando ya Gracián es tan sólo una imposición curricular de la educación secundaria, y por tanto de poca monta su mordedura, convenciéndonos de que: el pobre estado en el que se encuentra la literatura (argentina) ha producido una "superstición del estilo, una distraída lectura de atenciones parciales". Aquellos que padecen esta superstición identifican estilo no con eficacia -agrega Borges-, sino con habilidades "aparentes" del escritor: "sus comparaciones, su acústica, los episodios de su puntuación y de su sintaxis". ${ }^{12}$ Poner especial cuidado sobre la adjetivación es exhibido como otra grave dolencia, así como la presencia exuberante de "sorpresas en la juntura de los adjetivos con los sustantivos, aunque su finalidad general esté realizada". ${ }^{13}$ Continúa de la siguiente manera: "Oyeron que la concisión es una virtud y tienen por conciso a quien se demora en diez frases breves y no

${ }^{10}$ B. Gracián, Agudeza y arte de ingenio, pp. 245-246.

${ }^{11}$ De hecho el término ejemplo pertenece a una terminología, aunque el uso cotidiano del mismo haya rebajado sus aristas y especificidades. Poner un ejemplo implica una actividad teórica, es decir, proponer una cosa de naturaleza simple o esquemática y a la vez evidente para que esta simpleza y evidencia puedan traspasarse o intercambiarse con aquello que el ejemplo pretende aclarar. El ejemplo entonces pone en la palestra la idea de la evidencia, es decir, que es aquello que resulta evidente a primera vista, o más bien según el uso habitual del vocabulario o a partir de los sentidos, ambas son opciones posibles de uso de lo evidente. Además de convocar la intervención de nociones igualmente complicadas como la que encierra la palabra simple y esquemática.

${ }^{12}$ J. L. Borges, Discusión, p. 39.

${ }^{13}$ Idem. 
a quien maneje una larga". ${ }^{14} \mathrm{Y}$ redondea la crítica al calificar este estilo de "charlatanería de la brevedad", "frenesí sentencioso" que puede buscarse en "la dicción del Polonio natural, Baltasar Gracián". ${ }^{15}$ Lo que Borges deja sin decir es que la escritura de Gracián como la suya propia es un ejemplo de las preocupaciones que conducen el pensamiento a reparar en su lengua y obras, es decir, en el concepto y en la crítica del mismo.

La crítica, en Gracián y Borges, va asociada a una crítica de los usos del lenguaje, mostrando que las ambigüedades de sentido, lo paradójico, las perplejidades que hace nacer la escritura dependen de la lengua, entendida entonces como la historia del idioma, el tesoro de refranes y fórmulas comunes a una comunidad o pueblo; es decir, la lengua historizada, a la vez que las técnicas retóricas por cuyo intermedio conservamos y actualizamos esta tradición y que significa sobre todo un uso oportuno de los recursos de la lengua, que bien podrían estar allí sin que necesariamente los actualizáramos: la lengua es probable tanto como contingente.

Sutileza maliciosa, crítica intencionada, al fin, todo superior gusto la estima, porque lastima...

Consiste su artificio en glosar, interpretando, adivinando, torciendo, y tal vez inventándose la intención, la causa, el motivo de que obra, ya a la malicia, que es lo ordinario, ya el encomio. ${ }^{16}$

La crítica pertenece también al lector, ya que "Es menester que haya artificio y destreza en el que obra, ya verdadero, ya interpretado, y el notar aquella arte, y segunda intención sutil con que obra, es la crítica agudeza". ${ }^{17}$ "Así como el obrar con artificio y con refleja nace de la ventaja de ingenio, así el descubrir ese artificio, y el notarlo, es sutileza doblada" ${ }^{18}$ La crítica es pues la medida de la interpretación, o como bien dice Borges, de la lectura; se trata, más que de una ética en sentido habitual, de una regla que dirige las técnicas de lectura, una economía de la lectura, de sus fuerzas, antes que una cierta actitud moralizante sobre el trabajo del lector y el escritor.

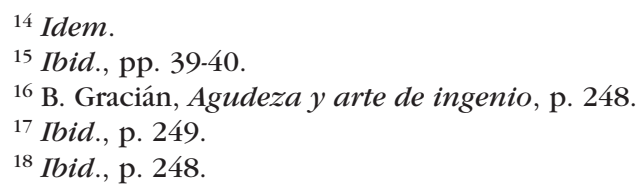

